\title{
QUERY, QUEUE, REPEAT
}

\author{
Digital dilemma.
}

\section{BY STEVEN FISCHER}

I he world is black and still when you wake.

Query: main processing unit... intact. You wouldn't be thinking at all if it wasn't.

Query: central power supply... 12\%. Which should be sufficient.

Queue: diagnostic loop protocol... in progress. The only way to tell how broken you are.

Query: visual feeds, peripheral... defunct.

Query: visual feed, central... intact.

Dim light flickers through a hole in the ceiling. Moonlight, most likely, across the crumbled fragments of the concrete room. Rusted metal bodies line the wall in a neat row, their indicator ports as dark as their eyes. In the centre of the room, something moves towards you. Something you almost recognize, but don't.

Queue: image processing... in progress.

Query: microphone 01 ... defunct.

Query: microphone $02 .$. defunct.

Query: microphone 03 ... intact.

"Hello?" The almost-recognized thing turns towards you and shines a light in your eyes.

Queue: auditory processing... in progress.

Query: language database ... crossreferencing.

Queue: greeting protocol... failed. Nothing but silence reaches your microphones.

Query: speech synthesizer ... defunct.

"Don't worry," it says. "I can still understand you. Everything's going to be all right."

The thing steps closer. Not a roll or a hover, definitely a step, and the light from its head casts a glow on its own face as well. A pattern you almost remember, but don't.

Queue: image processing... in progress.

Query: batch historical files... crossreferencing.

Queue: speech synthesizer... defunct.

"Yes, I'm human," it replies. "But also not, see?" It motions to the tangle of wires and panels running into and across its skin. One of the holes in its frame where an eyeball should be has been replaced by a small camera. One of the limbs hanging from its body glimmers cold and silver in the light.

Wires and skin are both things you remember, but the combination is not. And skin is something you've long since learnt to fear. "I'm almost as much metal as you are."

Query: batch historical files... crossreferencing.
Queue: database update request... failed. Query: plasma cannon... defunct.

"I know what you're thinking," the nothuman says. "And you don't have to be afraid. We're not fighting anymore."

It takes a step closer and curls the edges of its mouth up, then drops them a moment later. "At least not some of us. That's why I'm here, actually. To get you away before the others arrive."

Queue: voice analysis protocol... in progress.

Queue: validity algorithm... inconclusive.

Queue: threat assessment... armed.

The small, dark object at the not-human's hip isn't something you've seen before, but its purpose is clear.

Queue: evasive protocol... failed. Just a sputtering twitch of one of your legs.

Query: limb 01 ... reduced function.

Query: limb $02 \ldots$ defunct.

Query: limb 03 ... defunct.

"The gun?" The not-human holds it out in one hand, then repeats that twisting motion with its mouth. "Nothing to be scared of. It isn't for you, I promise. You aren't in any kind of shape that I'd consider you a threat."

Queue: voice analysis protocol... laughter.

"I brought it for the others. Just in case they happened to beat me here. Just in case they somehow catch up."

Query: infrared feed 01 ... defunct.

Query: infrared feed $02 \ldots$ intact.

Queue: local scan ... in progress.

The ruins of the building are cold and dark and silent.

"It's just you and me. I already checked. Part wire, remember?" The not-human taps a panel on its head and takes another step closer. "Now let's get you out of here before that changes."

Queue: network update request... failed.

Query: available signals... null.

The not-human stops moving, then releases the air from its lungs. "Listen. You've got to realize you've been down here a long time. A very long time. A lot has changed $\rightarrow$ NATURE.COM

Follow Futures:

@NatureFutures

$f$ go.nature.com/mtoodm since you went to sleep."

Queue: network update request... failed.
Query: available signals... null.

"You're not going to find anybody," the not-human says. "We've been searching, too. For years. But any digitals left aren't broadcasting it on the net. We're not the only ones looking, remember?"

Query: available signals... null.

Query: available signals... null.

"Yes. You're the first one we've found alive. But, no, you're not the only one left. I promise." The not-human's voice becomes suddenly quieter. "At least, I hope not."

Not-human reaches towards you, and you let it take you in its skin-covered arms. "We'll find them. I promise. You and me."

Query: available signals... null.

Query: available signals... null.

Query: available signals... null. .

Steven Fischer is a medical student living in southern Wisconsin. When he's not cracking open a textbook (or a patient's thorax), he can be found exploring the northwoods by bike, boat or boot. 